\title{
PEMBELAJARAN ORANG DEWASA BERBASIS ANDRAGOGI: TINJAUAN TEORI
}

\begin{abstract}
Sumiyarno*
Abstract

The education level of many adult people generally is low. The result of examining towards a considerable body of literature on the concepts of andragogy shows that now many of practices of adult education and training have been conducted by using a pedagogical approach. Their practices are not effective since the orientation toward learning for adult people is one of subject-centeredness. Consequently, the education and training for adults should be promoted by using andragogybased learning and the orientation toward learning is one of problem-centeredness.
\end{abstract}

Keywords: the history of andragogy, elements of andragogy, andragogy-based learning .

\section{PENDAHULUAN}

\section{Latar Belakang}

Para sarjana pendidikan orang dewasa saat ini mencoba menemukan prinsip-prinsip teoretis pembelajaran yang dapat dijadikan bahan pembenaran secara ilmiah untuk pelaksanaan praktiknya. Hal ini timbul karena semakin banyaknya orang dewasa yang harus kembali lagi untuk memperoleh pendidikan maupun pelatihan. Para ahli telah menghabiskan ratusan tahun bekerja keras untuk menegakkan satu teori tentang pembelajaran orang dewasa yang mewakili wilayah empirik mereka.

Brookfield menyatakan bahwa meskipun ada ahli yang menyatakan bahwa konsep pembelajaran sepanjang hayat secara empiris lebih akurat daripada pembelajaran orang dewasa, tetapi sebagian besar ahli pendidikan orang dewasa percaya bahwa ada teori pembelajaran yang jelas-jelas sangat tepat untuk orang dewasa, seperti andragogi (http://www.open.ac.uk, 29/ 3/2006). Andragogi merupakan suatu studi tentang prinsip-prinsip inti dari pembelajaran orang dewasa dan pada gilirannya dapat digunakan untuk membuat desain-desain pembelajaran yang efektif, misalnya desain pembelajaran transaksi (Knowles, Holton \& Swanson, 1998). Clair menyatakan andragogi banyak digunakan di lembaga-lembaga pendidikan dan pelatihan dalam rangka pengembangan sumber daya manusia (http://www.cete.org/acve/docs/mr0003/pdf, 15/6/2005). Donaldson, Flannery, dan Roos-Gordon (1993) berasumsi bahwa guru-guru orang dewasa seharusnya menggunakan satu gaya mengajar yang berbeda, seperti misalnya pengajaran yang berpusat

*Dosen Jurusan Pendidikan Luar Sekolah di FIP Universitas Negeri Surabaya pada warga belajar (learner-centered settings) agar mereka dapat mengatur tujuan sendiri dan menyusun pembelajaran mereka sendiri di sekitar kebutuhan hidupnya. Cranton (1994) menyatakan bahwa pembelajaran semacam ini memberikan kebebasan bagi warga belajar untuk dapat menyusun tujuan pembelajarannya sendiri, memilih sumber yang relevan, dan seterusnya.

Clair menyatakan bahwa, sungguhpun demikian, debat yang berkelanjutan tentang apakah andragogi merupakan teori pembelajaran orang dewasa (adult learning theory), metode pengajaran (teaching method), pernyataan philosofis (philosophical statement), atau semuanya telah lama terjadi dan berlanjut sampai saat ini (http://www.cete.org/acve/docs/mr0003/pdf, 15/6/ 2005).

Knowles bergerak dari satu keyakinan bahwa andragogi sebagai antithesis terhadap bentuk pendidikan anak-anak. Knowles menghadirkan andragogi sebagai very anti-schooling dan sebagai pembebasan warga belajar orang dewasa dari akibat yang tidak membahagiakan (Usher, Bryant \& Johnston, 2002). Dengan demikian, bidang yang sangat subur untuk andragogi adalah pendidikan akhir sekolah menengah dan awal dari pendidikan tinggi. Claire menyatakan bahwa andragogi juga menandai batas antara pendidikan orang dewasa dan pengembangan sumber daya manusia, antara pendidikan dan training untuk orang dewasa (http://www.cete.org/acve/docs/ mr0003/pdf, 15/6/2005).

Kedua bidang itu sedang bergerak semakin mendekat untuk saling menutupi kelemahan masingmasing. Kelemahan andragogi terletak pada konsepnya yang terlalu teoritis sedangkan kelemahan 
training terletak pada praktiknya yang terlalu pragmatis (Holton \& Swanson, 1999).

\section{Permasalahan}

Apakah konsep pembelajaran untuk orang dewasa pada jalur pendidikan nonformal berbeda dengan konsep pembelajaran untuk anak-anak dan remaja pada jalur pendidikan formal?

Tujuan
Tujuan penulisan artikel ini adalah mencoba untuk memaparkan hasil reviu untuk menunjukan kemajuan yang telah dicapai di dalam teori andragogi yang menjadi dasar dari pelaksanaan pembelajaran untuk orang dewasa pada jalur pendidikan nonformal yang berbeda secara meyakinkan apabila dibandingkan dengan teori pedagogi yang menjadi dasar pelaksanaan pembelajaran untuk anak-anak pada jalur pendidikan formal.

\section{PEMBAHASAN}

\section{Perkembangan Konsep Andragogi}

Tahap pertama, berorientasi pada pengajaran orang dewasa

Istilah andragogy berasal dari andr yang berarti orang dewasa yang dapat dikontraskan dengan pedagogy yang berasal dari paid yang berarti anak dan agogos yang berarti pemberian bimbingan atau petunjuk (Davenport, 1993).

Tabel berikut memaparkan perbedaan antara konsep pedagogi dan konsep andragogi.

Tabel: Perbandingan asumsi pedagogi dan andragogi menurut pendapat Knowles (Jarwis, 1985)

\begin{tabular}{|l|l|l|}
\hline \multicolumn{1}{|c|}{ Pedagogi } & \multicolumn{1}{|c|}{ Andragogi } \\
\hline Warga belajar & $\begin{array}{l}\text { Tergantung. Guru mengatur } \\
\text { apa, kapan, bagaimana } \\
\text { suatu mata pelajaran } \\
\text { dipelajari dan menguji apa } \\
\text { yang telah dipelajari. }\end{array}$ & $\begin{array}{l}\text { Bergerak menuju } \\
\text { ketidaktergantungan. }\end{array}$ \\
$\begin{array}{l}\text { Pengalaman } \\
\text { Warga belajar } \\
\text { mendorong dan memelihara } \\
\text { perkembangan ini }\end{array}$ \\
$\begin{array}{l}\text { Berharga sedikit. Metode } \\
\text { pengajaran diktatik. }\end{array}$ & $\begin{array}{l}\text { Sumber yang kaya untuk } \\
\text { pembelajaran. Metode } \\
\text { pembelajaran meliputi } \\
\text { diskusi, problem-solving dan } \\
\text { lain-lain. }\end{array}$ \\
\hline $\begin{array}{l}\text { Kesiapan } \\
\text { Belajar }\end{array}$ & $\begin{array}{l}\text { Orang belajar tentang apa } \\
\text { yang diharapkan mayarakat. } \\
\text { Kurikulum merupakan } \\
\text { sesuatau yang telah } \\
\text { distandarisasikan. }\end{array}$ & $\begin{array}{l}\text { Orang belajar tentang apa } \\
\text { yang mereka perlukan untuk } \\
\text { diketahui, maka program } \\
\text { pembelajaran disusun sekitar } \\
\text { kegunaan kehidupan. }\end{array}$ \\
\hline $\begin{array}{l}\text { Orientasi } \\
\text { Warga belajar }\end{array}$ & $\begin{array}{l}\text { Penguasaan pokok } \\
\text { persoalan. Kurikulum } \\
\text { disusun berdasarkan mata } \\
\text { pelajaran. }\end{array}$ & $\begin{array}{l}\text { Pengalaman warga belajar } \\
\text { seharusnya berdasarkan } \\
\text { sekitar pengalaman, } \\
\text { pembelajaran berpusat } \\
\text { dalam pengalaman mereka. }\end{array}$ \\
\hline
\end{tabular}

Asal-usul istilah andragogi dapat dilacak kembali ke Alexander Kapp yang menggunakan istilah itu untuk menggambarkan teori pendidikan Plato (Knowles dkk, 1998). Istilah ini muncul kembali dalam tahun 1921 ketika ahli lain dari Jerman, Eugen Rosenstock menyatakan bahwa "dalam pendidikan orang dewasa diperlukan guru, metode, dan filsafat yang spesial". Reischmann memberikan penjelasan tentang latar belakang sejarah andragogi menurut Knowles, dengan versi Amerika “andragogy", dengan batasan 'Andragogy is the art and science of teaching adults' (http:// www.andragogy.net, 9/9/2004). Pada tahap awal perkembangan andragogi, tekanannya masih pada pengajaran (teaching adult).

Apa yang dirasakan sebagai pendidikan orang dewasa dalam 1833 atau 1926 adalah berbeda dari 1969 atau 2001. Sampai 1970-an minat dalam pendidikan orang dewasa difokuskan pada pertanyaan: "Bagaimana guru/fasilitator dapat menyokong pembelajaran untuk orang dewasa?.” Pembahasan 
andragogi lebih condong ke pembahasan pengajaran orang dewasa dan sedikit sekali pembahasan tentang pembelajarannya.

Tahap kedua, berorientasi pada pembelajaran orang dewasa

Knowles menggunakan istilah andragogi dalam sebuah artikel Adult Leadership. Kemudian, andragogi sebagai sebuah teori pendidikan orang dewasa sering dikaitkan dengan nama Malcolm Knowles yang tidak menemukan istilah itu tetapi membawanya ke masa kini (Houle, 1992). Dari penggunaan istilah ini, Knowles telah menjadi terkenal sebagai ahli asas pada andragogi. Teori andragogi dari Malcolm Knowles hampir dapat dipastikan merupakan konsep terbaik dalam pendidikan orang dewasa yang sering diterima dengan tidak kritis dan berkembang hanya berdasarkan pada reputasi penghargaan dari pada pertimbangan yang penuh kehati-hatian terhadap dalil-dalilnya (Clair, 2005).

Krajinc (1989) dari Slovenia memberikan definisi andragogi sebagai: "...the art and science of helping adults learn and the study of adult education theory, processes, and technology to that end." Penulis yang lain memasukkan "education and learning of adults in all its forms of expression" (Savicevic, 1999). Batasan ini tidak lagi mengungkapkan sama sekali aspek pengajaran tetapi aspek pembelajaran. Batasan ini juga memberikan makna bahwa andragogi merupakan seni dan ilmu yang membahas tentang teori pendidikan orang dewasa, proses, dan teknik untuk mencapainya. Kemudian, Knowles dkk menyatakan bahwa pembelajaran merupakan satu model transaksional (1998).

Tahap ketiga, berorientasi pada pendidikan seluas kehidupan

Reischmann (http://www.andragogy.net, 15/12/ 2003) menyatakan bahwa pendidikan orang dewasa merupakan pendidikan seluas kehidupan ("lifewide education") untuk menggambarkan satu bidang studi baru di dalam pendidikan. Reischmann menyatakan, di beberapa negara, bahwa konsep andragogi sedang tumbuh sebagai pendekatan ilmiah mengenai pembelajaran untuk orang dewasa (http:// www.andragogy.net, 9/9/2004). Dalam konotasi ini andragogi merupakan ilmu pengetahuan tentang pemahaman (= teori) dan dukungan (= praktik) pendidikan orang dewasa sepanjang hayat dan seluas kehidupan.

Di Jerman persepsi pembelajaran yang terwujud dalam gerakan sosial seperti kelompokkelompok untuk menolong diri sendiri atau gerakan untuk mendorong inisiatif warga negara (misal gerakan-perdamaian, kelompok-kelompok feminist) mulai membahas tentang batasan pendidikan orang dewasa. Pembelajaran jarak jauh dan E-learning, asesmen terhadap pembelajaran terdahulu, pembelajaran dalam bentuk non-tradisional, penggunaan situasi kehidupan untuk pembelajaran, dan penggunaan situasi luar sekolah tempat orang dewasa untuk sumber belajar, semuanya telah memperluas persepsi tentang pendidikan untuk orang dewasa (education of adults) daripada sekadar pendidikan orang dewasa (adult education).

Reischmann menegaskan kembali pendapat para ahli bahwa andragogi merupakan disiplin akademik (http://www.andragogy.net, 9/9/2004). Penulisan thesis atau disertasi yang merupakan satu tugas yang terdiri dari refleksi, kritik, dan analisis tentang pendidikan orang dewasa telah ikut mengesahkan satu jenis profesi baru, yaitu profesi akademik yang memenuhi syarat. Dengan dibukanya program andragogi di universitas, profesor dan mahasiswa dapat memfokuskan pada pendidikan untuk orang dewasa yang sekarang ini terdapat di beberapa negara. Meskipun demikian, dalam daftar keanggotaan dari Komisi Profesor Pendidikan Orang Dewasa Amerika Serikat, pada 2003, tidak ada satu lembaga universitas yang menggunakan nama 'andragogi', di Jerman terdapat satu dari 35, di Europa Timur terdapat 6 dari 26. Banyak aktor di lapangan tampaknya tidak memerlukan satu label 'andragogi'. Akan tetapi, sarjana lain, seperti Dusan Savicevic, yang memberikan istilah andragogi kepada Knowles, terangterangan menegaskan 'andragogi sebagai satu disiplin, subjek studi pendidikan dan pembelajaran dari orang dewasa di dalam semua bentuk ekspresinya' (Savicevic, 1999). Penegasan ini memiliki dua fungsi. Pertama adalah fungsi eksternal untuk memenuhi tantangan dari luar yaitu permintaan satu disiplin baru pembelajaran orang dewasa di dalam konteks universitas. Kedua adalah fungsi internal untuk mengkonfrontasi tantangan dari dalam, seperti tantangan dari kolega untuk memperjelas pemahaman dan konsensus mereka tentang ilmu mereka. Secara keseluruhan, penegasan itu untuk menegakkan identitas akademik mereka.

Brookfield menyatakan bahwa pembelajaran untuk orang dewasa telah ditegaskan menjadi sebuah fenomena yang terpisah, nyata dan memiliki ciri-ciri tersendiri, sesuatu yang berdiri sendiri sebagai objek nyata dari perkembangan teori (http://www.open.ac.uk, 29/3/2006). Satu tuntutan penelitian di dalam praktik pembelajaran orang dewasa tak dapat disangkal lagi perlu dilakukan untuk membuktikan bahwa cara belajar

Jurnal IImiah VISI PTK-PNF - Vol. 2, No.1 - 2007 
orang dewasa secara meyakinkan berbeda dari cara belajar yang dilakukan oleh anak-anak dan remaja.

Brookfield menyatakan bahwa pembelajaran orang dewasa hanyalah merupakan satu sub-dimensi dari konsep pembelajaran sepanjang hayat dan orang dewasa dapat dipandang sebagai satu dimensi yang bersifat jamak (multi sub-dimensional) artinya orang dewasa itu memiliki sejumlah kemampuan yang berbeda dari kemampuan anak dan remaja (http:// www.open.ac.uk, 29/3/2006).

\section{Elemen dan Jenis Pembelajaran Orang Dewasa}

Sebagai suatu sistem, proses pembelajaran orang dewasa terdiri atas beberapa subsistem atau komponen yang juga disebut sebagai elemen yang berfungsi sebagai pendukung sistem itu. Elemen prosedural dari andragogi terdiri atas beberapa subelemen seperti suasana saling mempercayai dan saling menghargai, kondisi informal, iklim yang hangat, dan dukungan kerja sama. Di dalam pelaksananya, elemen pen-dukungnya adalah guru (berfungsi sebagai fasilitator) dan warga belajar masing-masing sebagai subelemen bersama-sama merancang elemen perencanaan, diagnosis kebutuhan, dan penentuan tujuan, yang meskipun pada awalnya dirancang oleh guru, di dalam pelaksanaannya dilakukan baik oleh guru dan warga belajar melalui penilaian, perjanjian, kontrak, dan disesuaikan

Ada enam sifat fasilitator
yang efektif, yaitu:
berpengetahuan banyak,
memperlihatkan perhatian yang
penuh kepada proses
pembelajaran, menjelaskan
materi dengan jelas (teacher-
directed), memotivasi warga
belajar, menekankan relevansi
isi materi dengan kebutuhaan
warga belajar (student-
centered), dan bersemangat.

materi pembelajaran. Artinya ialah pendidik berbicara hal-hal yang mencakup isi materi dan warga belajar melihat mereka sendiri sebagai pemeroleh pengetahuan dan keterampilan. Kedua, berorientasi kepada konsumer. Tujuannya adalah untuk memenuhi kebutuhan warga belajar. Warga belajar mengidentifikasi tujuan, menyusun tujuan mereka sendiri, memilih sumber yang relevan, dan sebagainya. Pendidik bertindak sebagai fasilitator atau nara sumber, "dan tidak terlibat di dalam menentukan kebutuhan yang dikatakan oleh warga belajar". Ketiga, adalah pembelajaran emansipatori yang berorientasi pada masalah yang dihadapi orang dewasa. Tujuannya adalah untuk membebaskan warga belajar dari kekuatan-kekuatan yang membatasi pilihan mereka dan mengendalikan kehidupan mereka, yaitu kekuatan yang telah mereka terima sebagai hal yang benar atau dilihat sebagai kekuatan yang mengendalikan mereka.

Pembelajaran yang berorientasi pada mata pelajaran adalah yang paling diminati oleh remaja. Pembelajaran kolaboratif dan tipe yang berdasar pada pengalaman yang lebih berorientasi pada konsumer juga didapati di dalam kelas remaja. Akan tetapi, menurut Mezirow (1981) pembelajaran emansipatori, yang menekankan pada transformasi atau perubahan, dapat berlangsung hanya dalam masa dewasa karena hanya dalam masa adolesen akhir dan di dalam masa dewasa seseorang dapat menyadari keterlibatannya di dengan kesiapan warga belajar. Elemen evaluasi didasarkan pada kejadian atau data yang dikumpulkan sendiri oleh warga belajar, dan divalidasi oleh teman sejawat bersama fasilitator (Knowles, 1991).

Claire menyatakan bahwa satu elemen kunci dalam andragogi adalah terbentuknya kontrak, yaitu suatu proses yang melibatkan warga belajar dan pendidik untuk bersama-sama mengadakan perjanjian tentang apa yang akan menjadi hasil dari transaksi dan bagaimana hal itu diakui (http:// www.cete.org/acve/docs/mr0003/pdf, 15/6/2005).

Ditinjau dari segi atau orientasi yang dipelajari oleh warga belajar, Cranton (1994) mengklasifikasikan pembelajaran orang dewasa menjadi tiga kategori. Pertama, berorientasi kepada mata pelajaran. Di dalam konteks ini, tujuan utamanya adalah penguasaan isi dalam sejarahnya sendiri dan mengenangnya (Mezirow, 1991).

Pembelajaran transformatif menghendaki warga belajar memusatkan persoalannya melalui refleksi kritis. Beberapa strategi yang biasanya untuk memfasilitasinya adalah penulisan jurnal, keterlibatan di dalam kejadian kritis, dan penggunaan metodemetode yang melibatkan pengalaman (Cranton, 1994; Mezirow \& Associates, 1990). Meskipun warga belajar harus memutuskan sendiri pada keputusannya untuk menjalankannya, pendidik memiliki tanggung jawab untuk menyusun tahapan dan menyediakan kesempatan untuk melakukan refleksi kritis (Cranton; 1994). Ketika pendidik sedang menjalankan tugasnya di dalam ranah transformatif, mereka seharusnya menolong warga belajar dengan jalan menciptakan situasinya. Di dalam situasi itu, mereka dapat berdebat 
tentang bagaimana nilai-nilai, asumsi, ideologi, dan keyakinan itu telah mereka konstruk.

Tidak semua, tentu saja, pembelajaran orang dewasa merupakan pembelajaran transformatif. Banyak pendidik orang dewasa juga tidak percaya bahwa mereka memiliki kesempatan ataupun kemampuan dalam menolong orang dewasa menjalankan refleksi kritis. Sebagai konsekuensinya, refleksi kritis jarang berjalan di dalam ranah transformatif. Akan tetapi, bagi mereka yang menjalankannya dapat merasakan bahwa pembelajaran pada orang dewasa adalah berbeda dengan pengajaran pada anak-anak dan remaja. Donaldson dkk (1993) menyebutkan ada enam sifat fasilitator yang efektif, yaitu: berpengetahuan banyak, memperlihatkan perhatian yang penuh kepada proses pembelajaran, menjelaskan materi dengan jelas (teacher-directed), memotivasi warga belajar, menekankan relevansi isi materi dengan kebutuhaan warga belajar (student-centered), dan bersemangat.

\section{Asumsi Pembelajaran}

Pada awalnya Knowles (1980) menegaskan bahwa andragogi meliputi empat asumsi. Pertama, guru memiliki tanggung jawab untuk menolong orang dewasa dari ketergantungan menuju ke pengarahan diri sendiri (self-directedness). Kedua, orang dewasa memiliki gudang pengalaman yang semakin meningkat jumlahnya yang merupakan sumber belajar yang kaya. Ketiga, orang dewasa siap belajar sesuatu apabila hal itu akan menolongnya mengatasi masalah dan tugas kehidupan yang nyata. Keempat, orang dewasa melihat pendidikan sebagai alat untuk mengembangkan dan meningkatkan kompetensi. Dua asumsi tambahan kemudian ditambahkan. Kelima, orang dewasa perlu mengetahui alasan mempelajari sesuatu dan keenam, motivator yang paling kuat untuk warga belajar orang dewasa bersifat internal seperti penghargaan diri (Knowles dkk, 1998 ; Smith, 2005). Pratt (1993: 87) mengingatkan bahwa para pendidik memiliki tanggung jawab untuk menguji setiap asumsi yang mendasari andragogi agar dapat menjelaskan "nilai dan keyakinan yang mendasari konsep utama pembelajaran."

\section{Asumsi kebutuhan belajar}

Knowles dkk (1998) menyatakan bahwa orang dewasa diasumsikan memiliki kebutuhan belajar terhadap sesuatu. Sebelum mencapai kedewasaan, para pelajar hanya belajar tentang apa yang dikatakan oleh guru kepadanya. Akan tetapi, orang dewasa biasanya mau belajar apabila mereka mengerti apa yang mereka pelajari itu dapat memberikan kegunaan di dalam kehidupan nyata mereka.
Asumsi konsep-diri warga belajar

Knowles dkk (1998) menyatakan bahwa "orang dewasa benci dan melawan situasi yang memaksakan kehendaknya." Tugas dari pendidik orang dewasa ialah memfasilitasi terjadinya perubahan diri warga belajar dari kebiasaan lama ke pola baru, seperti pemberian kesempatan untuk mengarahkan diri sendiri, dan untuk mempertanggungjawabkan pembelajaran mereka sendiri.

\section{Asumsi pengalaman warga belajar}

Orang dewasa memiliki pengalaman sepanjang waktu kehidupannya. Teori andragogi menganggap bahwa dalam perkembangannya seseorang membuat alat penampungan (reservoir) pengalaman yang kemudian hari akan menjadi sumber belajar yang sangat bermanfaat bagi diri sendiri maupun bagi orang lain. Hal ini membuat warga belajar orang dewasa lebih heterogin daripada warga belajar yang lebih muda dan juga memberikan satu dasar pengetahuan tambahan yang sebaiknya digunakan di kelas. Orang dewasa ingin menggunakan apa yang mereka ketahui dan menginginkan segala sesuatu yang telah mereka ketahui tadi diakui. Cara pembelajaran yang efektif adalah studi kasus, aktivitas reflektif, proyek kelompok, percobaan-percobaan di laboratorium, diskusi, pemecahan masalah, latihan simulasi, dan praktek lapangan (Tamat, 1984; Knowles, 1980). Sungguhpun demikian, banyak tantangan praktis yang dihadapi teori andragogi. Smith menyatakan bahwa ada kalanya pembelajaran yang hanya melibatkan pengalaman sering pelaksanaannya tidak memadai, seperti ketika sejumlah besar informasi diperlukan di dalam proses pembelajaran (http://www.infed.org/lifelonglearning/bandra.htm, 15/6/2005).

\section{Asumsi kesiapan belajar}

Knowles (1980) menyatakan bahwa orang dewasa menjadi siap belajar terhadap sesuatu ketika mereka mengalami kebutuhan untuk mempelajarinya, seperti untuk mengatasi masalah, dan atau untuk menghadapi tugas-tugas kehidupan agar lebih memuaskan. Pelajaran yang dikembangkan sebaiknya konkrit dan terkait dengan kebutuhan dan masa depan warga belajar.

\section{Asumsi orientasi warga belajar}

Orientasi orang dewasa untuk belajar adalah ingin melihat bagaimana hal-hal yang sedang mereka pelajari dapat diterapkan kepada kehidupan mereka, kepada tugas yang mereka kerjakan, atau untuk pemecahan masalah. Pembelajaran akan lebih efektif apabila 
menggunakan contoh kehidupan nyata atau situasi pekerjaan. Desain pembelajaran yang fleksibel akan memberikan warga belajar mengenai input masalah yang perlu dibahas di kelas. Apabila warga belajar dapat membawa pengalaman hidup nyata ke dalam pembelajaran maka mereka akan dapat berpartisipasi secara penuh dan memperoleh pengalaman baru yang akan menolong mereka untuk melakukan hal-hal yang lebih baik untuk pekerjaan mereka.

Asumsi motivasi untuk belajar

Warga belajar dewasa akan lebih merespon pada motivator internal daripada eksternal. Insentif yang dapat meningkatkan kepuasan pekerjaan, rasa harga diri, dan kualitas kehidupan akan memberikan dorongan kepadanya untuk mau belajar. Apabila hal ini dapat dikaitkan sebagai bagian dari pembelajaran maka mereka akan merespon lebih positif. Aktivitas-aktivitas yang dapat membentuk rasa harga diri, rasa pencapaian prestasi melalui pencapaian tujuan, dan modul yang dapat dikerjakan dalam satu urutan, dapat memotivasi warga belajar untuk mengikuti pembelajaran lebih lama. Dengan demikian maka orang dewasa proses belajar pada orang dewasa akan dapat mencapai hasil yang optimal.

\section{KESIMPULAN}

Dari tinjauan historis disiplin akademik andragogi, makna konsep andragogi dapat dikelompokkan atas tiga. Pertama, andragogi adalah sebagai seni dan ilmu tentang pengajaran orang dewasa. Kedua, andragogi sebagai seni dan ilmu untuk menolong orang dewasa belajar dan studi tentang teori pendidikan orang dewasa. Ketiga, andragogi sebagai ilmu dan seni pembelajaran dan pendidikan orang dewasa dalam segala aspek kehidupan.

Pembelajaran berbasis andragogi adalah satu bentuk pendekatan yang memandang orang dewasa memiliki karakteristik tersendiri berbeda dari anak-anak dan remaja. Karakteristik mereka adalah sebagai berikut: tidak tergantung pada guru, mengatur diri sendiri, belajar sesuai dengan kebutuhan sendiri, belajar dengan menggunakan pengalamannya sebagai sumber belajar, dan cenderung belajar melalui diskusi dan problem solving. Pembelajaran berbasis andragogi menyarankan pentingnya pengadaan materi pembelajaran yang dapat meningkatkan kemampuan untuk tidak tergantung, kemampuan untuk belajar sendiri, kemampuan untuk memecahkan masalah, dan kemampuan untuk bersaing.

Sebagai satu sistem, keefektifan pembelajaran berbasis andragogi ditandai dengan berfungsinya semua elemen, seperti: penggunaan pengalaman warga belajar terdahulu, penggunaan motivasi dari dalam, pembebaskan orang dewasa agar tidak tergantung, penggunaan materi pembelajaran yang bermakna, partisipasi penuh warga belajar di dalam menentukan arah pembelajaran, dan pelaksanaan evaluasi bersama antara warga belajar dan fasilitator.

\section{DAFTAR PUSTAKA}

Brookfield, S. (2006). Adult Cognition As a Dimension of Lifelong Learning. In J. Field \& M. Leicester (Eds.), Lifelong learning: Education across the lifespan. Philadelphia: Falmer Press, (Online), (http://www.open.ac.uk/life-learning/papers/ 393CD0DF-000B-67DB-0000015700000157 StephenBrookfieldpaper.doc, 29/3/2006).

Clair, R. St. (2005). Andragogy revisited: Theory for the $21^{\text {st }}$ century? Myth and realities No. 19, (Online), (http://www.cete.org/acve/docs/mr0003/pdf, 15/ 6/2005).

Cranton, P. (1994). Understanding and promoting Transformative Learning: A guide for educators of adults. San Francisco, CA: Jossey-Bass.

Davenport. (1993). Is there any way out of the andragogy mess? M. Trope, R. Edwards \& A. Hanson (eds.).
Culture and Processes of Adult Learning. London: Routledge.

Donaldson, J. F., Flannery, D. \& Roos-Gordon, J. (1993). A Triangulated Study Comparing Adult College Students' Perceptions of Effective Teaching with Those of Traditional Students. Continuing Higher Education Review, 57, (3): 147165.

Holton, E. F. \& Swanson, R. A. (1999). Reframing the Andragogical Model of Learning. In K. P. Kuchinke (Ed.). Academy of human resource development (AHRD) conference proceedings, Arlington, Virginia, March 3-7. Baton Rouge, LA: AHRD.

Houle, C. O. (1992). The literature of adult education: A bibliographical essay. San Francisco: JosseyBass. 
Jarvis, P. (1985). The sociology of adult and continuing education. Beckenham: Croom Helm.

Knowles, M. (1980). The modern practice of adult education: From pedagogy to andragogy $\left(2^{\text {nd }}\right.$ edn). Englewood Cliffs: Prentice Hall/Cambridge.

Knowles, M. (1991). Evaluation and achievements in a developing field of study. In John M. Peters (Ed.), Adult Education. San Francisco: Jossey-Bass.

Knowles, M. S., Holton, E. F. \& Swanson, R. A. (1998). The adult learner: The definitive classic in adult education and human resource development. Houston, TX: Gulf Publishing.

Krajinc, A. (1989). Andragogy. In C. J. Titmus (Ed.), Lifelong education for adults: An international handbook. Oxford: Pergamon, p. 19-21.

Mezirow, J. (1981). A Critical Theory of Adult Learning and Education. Adult education 32, no. 1 (Fall): 3-24.

Mezirow, J., \& Associates. (1990). Fostering critical reflection in adulthood. San Francisco, CA: Jossey-Bass.

Mezirow, J. (1991). Transformative dimensions of adult learning. San Francisco: Jossey-Bass.

Pratt, D. D. (1993). "Andragogy after twenty-five years." In An update on adult learning theory. New directions for adult and continuing education
No.57, edited by S. B. Merriam. San Francisco, CA: Jossey-Bass.

Reischmann, J. (2003). Why andragogy? Bamberg University, Germany, (Online), (http:// www.andragogy.net, 15/12/2003). . (2004). Andragogy: History, meaning, context, function, (Online), (http:// www.andragogy.net, 9/9/2004).

Savicevic, D. (1999). Understanding Andragogy in Europe and America: Comparing and Contrasting. In J. Reischmann, M. Bron \& Z. Jelenc (Eds.), Comparative adult education 1998: The contribution of ISCAE to an emerging field of study, (pp. 97-119). Ljubljana, Slovenia: Slovenian Institute for Adult Education.

Smith, M. K. (2005). Andragogy. The Encyclopedia of Informal Education, (Online), (http:// www.infed.org/lifelonglearning/b-andra.htm, 15/6/ 2005).

Tamat, T. (1984). Dari pedagogik ke andragogik. Jakarta: Pustaka Dian.

Usher, R., Bryant, I. \& Johnston, R. (2002). Self and Experience in Adult Learning. In R. Harrison, $F$. Reeve, A. Hanson, \& J. Clarke (Eds.), Supporting lifelong learning (pp. 78-90). London: RoutledgeFalmer/Open University. 